ËESTI NSV TEADUSTE AKADEEMIA TOIMETISEED. VII KÖIDE BIOLOOGILINE SEERIA. 1958, NR. 2

ИЗВЕСТИЯ АКАДЕМИИ НАУК ЭСТОНСКОИ ССР. ТОМ VII СЕРИЯ БИОЛОГИЧЕСКАЯ. 1958, № 2

\title{
РАЗВИТИЕ ПЛОДОВЫХ ТЕЛ И СПОРУЛЯЦИЯ ТРУТОВЫХ ГРИБОВ *
}

\author{
Э. Х. ПАРМАСТО, \\ кандидат биологических наук
}

Для получения полного представления о жизнедеятельности трутовых грибов необходимо детально ознакомиться с особенностями появления и развития их плодовых тел и споруляции (выделение спор). Әто тем более существенно, что в борьбе с опасными в хозяйственном отношении трутовыми грибами знание биологии их размпожієния и распространения должно иметь первостепенное значение.

Несмотря на всю важность вопроса, сделано в этом отношении еще мало. Қажется прямо курьезным, что у многих обычных видов (напр., Fomes fomentarius Fomitopsis rosea, Trametes suaveolens, Daedalea quercina и др.) ** споры наблюдаются исключительно редко (Bose, 1930, стр. 432; Бондарцев, 1936, стр. 147; К. Lohwag, 1940, стр. 403). Нередко отсутствие спор делает почти невозможным правильное определение вида. Главной причиной этого, по-видимому, является то обстоятельство, что споруляция многих трутовых грибов происходит обычно в то время года, когда микологи лишь случайно проводят полевые работы.

Изучение споруляции трутовых грибов ведется только с начала настоящего столетия: соответствующие наблюдения и опыты касаются лишь 25 видов трутовых грибов. Қ сожалению, большая часть наблюдений проведена в лабораторных условиях, ввиду чего данные, полученные таким путем, мало отражают пронсходящее в природе. Исследований, проведенных на большем числе экземпляров с применением надлежащей методики, строго говоря, только четыре: наблюдения Борисова (1940) о споруляции Phellinus igniarius и Ph. tremulae, Персивала (Percival, 1933) - о Ph. pini, Бьёрнекера (Bjørnekaer, 1938) - о споруляции 9 видов и Райли (Riley, 1952) - о Ph. tremulae.

\section{Методика исследования}

Главным препятствием на пути более широкого изучения споруляции является сложность и неточность методики наблюдений.

Наиболее простым способом качественного наблюдения споруляции является непосредственное наблюдение. При наличии благоприятных условий оснещения (напр., падение солнечных лучей через листву на плодовое тело, находящееся в тенистом месте), облачка спор, возникающие при обильной споруляции, видны невооруженным г.лазом. Но такое явление наблюдается сравнительно редко (см. Buller, 1922, стр. 100 и Бондарцев, 1936). Автору удавалось изредка наблюдать подобную интересную картину прн стационарных исследованиях в лесничестве Ярвселья (Laetiporus sulphureus - 10 VI 1953; Tyromyces fissilis - в Кингисеппском районе 4 IX 1953; Gloeoporus tschulymicus - 14 VI, 8 VIII 1954; Phaeolus Schweinitzii - 14 VIII 1953; Fomes fomentarius - $26 \mathrm{~V}$ 1954; Fomitopsis pinicola - $26 \mathrm{~V}$ 1954; Ganoderma applanatum - 30 VI, 30 VII, 14 VIII и 13 X 1953, 8 VII и 23 VIII 1954).

* Дополненный и расширенный текст доклада, представленного на втором делегатском съезде Всесоюзного ботанического общества 13 мая 1957 г.

** Номенклатура трутовых соответствует примененной в монографии А. С. Бондарцева (1953), вследствие чего авторы видов здесь не указываются. 
Применяя эффект Тиндаля, дающий возможность установить при боковом освещении наличие микроскопических частиц, Бёллер (Buller, 1909) провел наблюдения в тємной комнате при помощи узкого луча света, направленного под плодовое тело. Таким образом ему удалось наблюдать споруляцию у некоторых видов. Для получения такого же эффекта Уайт (White, 1920) пользовался фонарем, наблюдая споруляцию ночью в природной обстановке у Fomes fomentarius. Недостатком этого остроумного метода является возможность пользоваться им только в лаборатории или в темноте.

При микроскопической разработке гербарного материала можно выяснить, когда собраны и в какой стадии развития находятся плодовые тела, имеющие развитый гименитальный слой и зрелые споры; при этом полезно отметить, имеются ли споры только единичные, или же в большом количестве. Әтот мало использованный метод дает возможность получить много дополнительных данных.

Мёллер (Möller, 1904) для исследования споруляции применял размачивание плодовых тел в воде (особенно замерзших плодовых тел) с последующим исследованием в лаборатории; к сожалению, он не дает более подробного описания своей методики, но, очевидно, полученные результаты не показывают точно, происходнт ли в прнродных условиях в данное время споруляция.

Все остальные методы и приемы исследования базируются на том явлении, что споры, падая на листочек бумаги, расположенный под гименофором, скопляются в внде налета, наблюдаемого либо невооруженным глазом, либо при помощи микроскопа. Некоторые исследователи (White, 1920; Bailey, 1941a, 1941b; Riley, 1952 и др.) вместо бумаги применяли предметные стекла.

Многие авторы пользовались описанным методом для наблюдения споруляции у плодовых тел, принесенных в лабораторию вместе с куском древесины меньшей или большей величины (Мейер, 1936; Buchwald, 1938; Buchwald et Hellmers, 1946; Fischer, 1935; Hirt, 1928, 1932; Mac Donald, 1937; Snell, 1922). Как бы удобна ни была для исследователя такая методика, в лаборатории результат исследований искажается не только условиями температуры, влажности и питания, отличающимися от природных, но и еще больше в результате неизбежного изменения направления трубочек гименофора, в природе ориентированных отвесно. Вследствие этого быстро начинается вегетативный рост краев пор (Bailey, 1941a, стр. 199) и плодовое тело спорулирует недолго.

Накоплению выделенных спор на бумаге или предметном стекле мешают воздушные течения, относящие большинство их в сторону. Для предотвращения мешающих течений воздуха Персивал (Percival, 1933) окружал плодовое тело цилиндрической жестяной посудой, плотно прикрепленной к стволу дерева, а Борисов (1940) - деревянным ящиком, имеющим стеклянную переднюю стенку. Недостатком этих приемов является нахождение плодовых тел в условиях температуры и влажности, отличающихся от нормальных, а также их трудоемкость, позволяющая проводить наблюдения только над небольшим количеством плодовых тел.

Бьёрнекер (Bjørnekaer, 1938) для ловли спор использовал металлические коробочки - пробки от пивных бутылок, на дно которых клал листочек бумаги; коробочку в этом случае припаивают к полоске жести, которую гвоздиком прикрепляют к нижней стороне плодового тела. Недостатком этого метода можно считать постоянное повреждение плодового тела (гвоздиком); кроме того, спороуловители довольно быстро ржавеют и их нужно запасать в большом количестве. Қак показывали наблюдения в стационаре Ярвселья, прикосновение металлического предмета (грани спороуловителя) к гименофору нередко уже через несколько дней влечет за собой гибель прилегающей части гименофора.

Неудовлетворительной является также и методика количественного учета споруляцин. Некоторые авторы (Percival, 1933; Bjфrnekaer, 1938; Борисов, 1940) определяли сравнительное количество спор, выделенных за какой-то период, глазомерно. Другие (Percival, 1933; Riley, 1952) определяли количество спор, упавших на предметное слекло, путем микроскопирования. Последний прием является также неточным, так как даже в закрытом месте (в ящике, окружающем плодовое тело) большая часть спор уносится воздушными течениями. По наблюдениям, проведенным в стационаре, на листочек бумаги, расположенный на расстоянии 1 мм от гименофора, спор попадает в десятки раз больше, чем на листочек, находящийся на 1 см ниже.

Более или менее все споры удается улавливать только методом, примененным Бондарцевым (1936) и Бухвальдом и Хелмерсом (Buchwald et Hellmers, 1946), a именно: плодовое тело обвертывается снизу листом бумаги, плотно прикрепленным к краям шляпки: на него падают все споры, выделенные за определенный промежуток ьремени. Определение количества спор уже не представляет трудности. Но таким сбразом можно провести наблюдения одного и того же плодового тела только в отдельных случаях или на протяжении короткого времени: закрытый бумагой гименофор находится в условиях повышенной влажности, что не соответствует наблюдасмому в природе и изменяет ход споруляции. 
Таким образом, пока отсутствует метод количественного изучения споруляции, который соответствовал бы двум основным требованиям - сохранять природную сбстановку и улавливать более или менее полно все выделяющиеся споры.

Для наблюдения споруляции у многих экземпляров на протяжении длительного времени (2 года) была применена с некоторыми изменениями методика Бєёрнекера (Bjørnekaer, 1938). На дно коробочки (пробки от лимонадной бутылки) опускался диск - темно-лиловая глянцевитая бумага; коробочку при помощи упругой жестяной полоски помещали под гименофор, на расстояние $1-2$ мм под нижнюю поверхность плодового тела. Жестяная полоска прикреплялась гвоздиками к стволу дерева или к пню. Коробочка лежала свободно на вогнутом конце полоски, что способствовало более быстрому и удобному перемещению коробочек во время регулярных наблюдений. Выделяющиеся споры, попадая на темную блестящую бумагу, образуют, даже при очень небольшом количестве, налет, видимый невооруженным глазом. Повторная проверка при помощи микроскопа показала, что, исключая случай, когда в коробочку пппадала дождевая вода, нет никакой надобности в применении микроскопа для выявления наличия спор. Количество выделенных спор оценивалось как отсутствующее, малое, среднее или обильное.

Ниже приводятся некоторые общие данные по характеристике места проведения стационарных наблюдений. Стационар находился в учебно-опытном лесхозе «Ярвселья» Эстонской сельскохозяйственной академин (Ряпинаский район). Участок наблюдений был расположен на сравнительно большом равнинном массиве леса; на тсритории стационара встречались разные типы ельников, в том числе и заболоченные. Средняя годовая температура на стационаре $4,3^{\circ}$; температура наиболее теплого месяца (июля) $17,7^{\circ}$. Осадков в году в среднем бывает $450-500$ мм, в том числе от мая до сентября - 302 мм; на тот же период дней с осадками бывает в среднем 65 (Mathiesen, 1927). Наблюдения производились через каждую неделю или с двухнедельными перерывами, с 20 апреля до 25 декабря 1953 г. и с 15 марта до 10 декабря 1954 г.; 3 июня 1955 г. проверялась перезимовка плодовых тел в течение зимы 1954/55 г. Для разрешения некоторых частных вопросов временами проводились ежедневные наблюдения, продолжавшиеся от 3 дней до 1 месяца (20-22 IV 1953 г., 14-18 IV, 11-17 V, 15 VII - 15 VIII, 11-14 XI 1954 г.). В июле и августе 1954 г. при проведении наблюдений автору помогали студентки Тартуского государственного университета Кох и Реннит.

Наблюдения проведены над 56 видами трутовых грибов (220 образцов). Прохождение одного и того же постоянного маршрута позволяло замечать появление новых плодовых тел и своевременно начинать наблюдения за их споруляцией. Подавляющее большинство экземпляров находилось на территории радиусом примерно в 0,5 км, в центре которой был установлен недельный термограф и гигрограф на высоте 0,1 м от земли, а также максимальный и минимальный термометры. Сведения о количестве осадков были получены из метеорологического пункта лесхоза, находящегося в 1,5 км от места наблюдения.

\section{БИОЛОГИЧЕСКИЕ ГРУППЫ ТРУТОВЫХ ГРИБОВ}

По продолжительности жизни плодовые тела трутовых грибов обычно разделяются как на одно- и многолетние, так, хотя и реже, и на двухлетние (напр. Бондарцев 1953); к последним причисляют, по-видимому, только те виды, которые способны случайно продолжать свою вегетацию на второй год (напр., Coltricia perennis). Бьёрнекер (Bjørnekaer, 1938) группировал трутовые грибы на основе периодов споруляции; но так как сн не принимал в'о внимание особенности развития плодовых тел, то эта классификация носит довольно формальный характер.

Наблюдения в Эстонской ССР показали, что среди трутовых грибов можно различать 3 биологические группы, сильно отличающиеся друг от друга циклом развития плодовых тел и временем споруляции, а именно: с однолетними, однолетними-зимующими и многолетними плодовыми телами. Рассмотрим каждую из этих групп отдельно, 


\section{Однолетние плодовые тела}

Наблюдения в стационаре, а также литературные данные позволяют к числу «однолетних» отнести следующие виды: Fibuloporia mollusca, Podaporia sanguinolenta, Ceraporia viridans, C. incarnata, Chaetoporellus Litschaueri, Chaetoporus corticola, Hapalopilus aurantiacus, H. fibrillosus, $H$. nidulans, Gloeoporus Bourdotii, G. tschulymicus, Tyromyces lacteus, $T$. albellus, $T$. caesius, $T$. erubescens, $T$. fragilis, $T$. undosus, $T$. albidus, $T$. floriformis, T. fissilis, Spongipellis Litschaueri, Laetiporus sulphureus, Piptoporus betulinus, Ischnoderma resinosum, Phaeolus Schweinitzii, Inonotus radiatus, $I$. rheades, Coltricia perennis, Polystictus tomentosus, $P$. circinatus, Polyporus squamosus, P. varius, P. picipes, Ganoderma lucidum, Abortiporus borealis и др.

Однолетние плодовые тела трутовых грибов появляются в' условиях Эстонской ССР обычно в июле и августе, т. е. в наиболее теплые месящы года. У некоторых видов плодовые тела могут появляться и раньше (начиная с мая) или позднее (до октября). Даже в один и тот же год время появления плодовых тел одного и того же вида заметно в'арьирует; поэтому время находок (напр., с июля по октябрь), которое часто приЕодится в определителях, не дает представления о продолжительности жизни отдельных плодовых тел, так как последняя обычно значительно короче.

Плодовые тела на одном и том же мицелии появляются не ежегодно. Так, осенью 1949 г. в гор. Тарту на стволе клена было найдено плодовое тело Spongipellis L.tschaueri и до сих пор (1956 г.) новых плодовых тел там не образовалось. В 1953 г. в Ярвселья на корнях лиственницы можно было наблюдать развитие двух плодовых тел Phaeolus Schweinitzii; в 1954 г. новых плодовых тел там не появилось; то же самое происходило с Polyporus varius, найденным поблизости.

С другой стороны, можно привести примеры последовательного образования плодовых тел: в Ярвселья на стволе одной осины ежегодно (1950-1955) наблюдались глодовые тела Laetiporus sulphureus; ежегодно (1949-1956) появляются в некоторых местах г. Тарту шляпки Polyporus squamosus.

Однолетние плодовые тела растут довольно быстро и нередко достигают нормальных размеров' в течение одной-двух недель (за исключением Piptoporus betulinus, которому требуется до 4 недель или даже больше), и только после этого идет образование трубчатого слоя. Споруляция начинается тогда, когда трубочки уже имеют длину $0,5-1$ мм и продолжается вместе с удлинением трубочек обычно 2-4 недели, а у некоторых видов (Podoporia sanguinolenta, Piptoporus betulinus, Coltricia perennis и др.) и еще дольше. Споруляция происходит, по-видимому, без больших перерывов. Так как однолетние плодовые тела не имеют особых приспособлений, противодействующих испарению воды, то скорость роста и интенсивность споруляции их зависят от влажности воздуха; при резком снижении последней споруляция может ослабевать или временно прекращаться сов'ем - особенно у сапрофитов, влажность субстрата которых в засушливую погоду заметно уменьшается (Fibuloporia mollusca, Gloeof'orus tschulymicus, Laetiporus sulphureus).

Гибель и разложение плодовых тел большинства «однолетних» видов не имеет прямой связи с метеорологическими условиями, а зависит от окончания споруляции. Очень часто разложение плодовых тел вызывается насекомыми и их личинками. Споруляция этих видов происходит обыкновенно тогда, когда средняя температура воздуха удержив'ается в пределах $12-23^{\circ}$ (или выше).

Плодовые тела других видов (Fibuloporia mollusca, Podoporia sanguinolenta, Piptoporus betulinus, Inonotus radiatus, Coltricia perennis) 
сохраняются дольше; появившиеся в более илй менее теплый период, развиваются до снижения температуры (средней и минимальной) ниже $0^{\circ}$ и только тогда погибают. Спорулящия у этих видов происходит даже при довольно низких температурах $\left(2,5-5^{\circ}\right)$.

Исключением среди других однолетних яв'ляется длительность жизни плодовых тел Fibuloporia mollusca, которые образуются уже весной (в мае) и способны спорулировать в' течёние 5 месяцев.

\section{Однолетние-зимующие плодовые тела}

В литературе имеются данные о наличии некоторых видов уже ранней весной, при этом предполагают, что плодовые тела образуются сразу же после таяния снега. Бондарцев (1953, стр. 79) отмечает, что плодовые тела Bjerkandera adusta, B. fumosa, Coriolus zonatus, C. versicolor, Coriolellus serialis, Polyporus brumalis «начинают появляться в наших широтах сразу вслед за таянием снега, в это же время у них почти в'сегда можно находить и споры». Бурдо и Гальзен (Bourdot et Galzin, 1928) указывают, что некоторые виды, встречающиеся в течение всего года, наблюдаются главным образом весной и осенью. В начале наших наблюдений (весна 1953 г.) в стационаре Ярвселья было большое количество плодовых тел многих видов трутовых грибов, но ни у одного из них не было заметно никакого роста.

Наблюдения в стационаре, а также и в других частях Эстонской ССР, разработка гербарных материалов и наблюдения зимовки отмеченных образцов в 1954/55 гг. доказали, что имеется целая группа видов, плодовые тела которых появляются летом, зимуют и разрушаются следующим летом, т. е. видов с однолетними-зимующими плодовыми телами. Сравнительно лучше удалось изучить в' этом отношении Coriolellus serialis и Tyromyces aneirinus. Приведенные данные, особенно в отношении остальных видов, разумеется, требуют дополнительных наблюдений и, несомненно, дальнейшими исследованиями будет обнаружено еще немало видов с однолетними зимующими плодовыми телами.

Нами изучалась споруляция у следующих видов: Chaetoporus euporus, Tyromyces semipileatus, T. aneirinus, T. resinascens, Bjerkandera adusta, B. fumosa, Coriolus versicolor, C. zonatus, C. sinuosus, Coriolellus serialis, C. flavescens, Antrodia mollis.

Однолетние-зимующие плодовые тела появляются летом - с июня гіо сентябрь; рост их происходит довольно медленно, обычно почти в течение месяца и бывает более интенсивным при теплой и сырой погоде. В конце лета и осенью наблюдается первый споруляционный период, длящийся 2-12 недель и оканчивающийся с падением температуры ниже $0-2^{\circ}$.

Продолжительность жизни плодовых тел зависит от условий среды. Нередко часть их погибает уже осенью, другая - отчасти даже до начала споруляции (главным образом) разрушается насекомыми. В других случаях плодовые тела при благоприятных условиях могут жить в течение нескольких лет (Coriolus sinuosus, Antrodia mollis). Amyloporia xantha является, по-видимому, видом, который в зависимости от условий местообитания может быть или однолетним-зимующим, или жить несколько лет, или даже еще дольше (f. crassa).

Зимующие плодовые тела, даже не покрытые снегом, выносят длительную температуру ниже $-15^{\circ}$ и минимальные температуры - $25^{\circ}$ и даже ниже (февраль 1954 г.). Весной, при повышении температуры (постоянно выше $0^{\circ}$ ), начинается второй период споруляции, который длится $4-10$ 
недель; плодовые тела разрушаются с мая по август или даже в сентябре (Antrodia mollis), причем нередко большое значение имеют насекомые.

Споруляция может совершаться при довольно низких температурах, например в дни, когда максимальная температура не превышает $3^{\circ}$ (Tyromyces aneirinus, Bjerkandera fumosa), но также и при довольно высокой средней температуре (до $20^{\circ}$ и выше). Как у видов с однолетними плодовыми телами, так и у этой группы епоруляция зависит от влажности воздуха и временно прекращается при снижении последней; особенно ясно это было выражено в середине мая 1954 г., когда перерыв в выделении спор наблюдался почти у всех исследуемых видов.

Для проверки зимовки некоторых видов в ноябре 1954 г. в разных частях лесничества Ярвселья были отмечены некоторые хорошо развитые плодовые тела; 3 VI 1955 г. их состояние проверялось. Результаты изложены в таблице.

\begin{tabular}{|c|c|c|c|}
\hline Вид & $\begin{array}{c}\text { Коли- } \\
\text { чество } \\
\text { плодовых } \\
\text { тел }\end{array}$ & $\begin{array}{l}\text { Из них } \\
3 \text { VI } 1955 \text { г. } \\
\text { были живы }\end{array}$ & $\begin{array}{c}\text { Примечание } \\
\text { (3 VI 1955 г.) }\end{array}$ \\
\hline Chaetoporus euporus & 3 & 3 & $\begin{array}{l}\text { Все с обильными спо- } \\
\text { рами }\end{array}$ \\
\hline Tyromyces aneirinus & 11 & 11 & $\begin{array}{l}\text { Уже побуревшие, но } \\
\text { все с обильными } \\
\text { спорами }\end{array}$ \\
\hline Bjerkandera adusta & 6 & 6 & $\begin{array}{l}\text { Все с обильными спо- } \\
\text { рами }\end{array}$ \\
\hline $\begin{array}{l}\text { Coriolus versicolor } \\
\text { C. zonatus }\end{array}$ & $\begin{array}{l}1 \\
4\end{array}$ & $\begin{array}{l}1 \\
3\end{array}$ & $\begin{array}{l}\text { Co спорами } \\
\text { Живые с обильными } \\
\text { спорами }\end{array}$ \\
\hline
\end{tabular}

\section{Многолетние плодовые тела}

Нами изучалась споруляция следующих видов: Podoporia vitrea, Anisomyces odoratus, Fomes fomentarius, Fomitopsis rosea, F. pinicola, $F$. annosa, $F$. unita var. multistratosa, $F$. Stellae, Phellinus igniarius, $P h$. tremulae, $\mathrm{Ph}$. laevigatus, $\mathrm{Ph}$. ribis, $\mathrm{Ph}$. nigrolimitatus, $\mathrm{Ph}$. ferrugineofuscus, Ph. pini var. pini, Ph. pini var. abietis, Ganoderma applanatum, Oxyporus populinus, Daedalea quercina. В отношении некоторых видов наблюдения не позволяют еще прийти к окончательному решению, принадлежали ли они к однолетним-зимующим или даже к многолетним (Cerrena unicolor, Hirschioporus abietinus).

Развитие многолетних плодовых тел и их споруляция происходит не у всех видов одинаково. У большинства видов образование гименофора происходит летом, а споруляция - в два периода: первый - летом и осенью, второй - весной. У одних видов преобладающее значение имеет гервый, у других - второй, а у некоторых то или другое может вовсе отсутствовать. У Ganoderma applanatum образование гименофора (нового слоя трубочек) начинается весной; споруляция наблюдается в течение одного периода - с весны до осени.

Появление новых плодовых тел наблюдается летом, обычно с июня по август; нарастание нового трубчатого слоя происходит (исключая Ganoderma applanatum) примерно с июня или июля до сентября - во время самых благоприятных условий температуры. Ни у многолетних, ни у других трутовых грибов' никакого роста ранней весной (в марте, апреле, обынно и в мае) не обнаружено. 
Наблюдения показали, что у многослойных плодовых тел ежегодно нарастает только один новый слой трубочек; у некоторых же образцов таковой иногда вообе не образовывался (Phellinus igniarius, Ph. pini var. abietis). То же отмечает и Мёллер (Möller, 1904, стр. 707) в отношении Ph. pini var. pini: у части плодовых тел ежегодного прироста гименофора не бывает, иногда старое, как бы уже мертвое плодовое тело через несколько лет вдруг образовывает новый слой гименофора. Хирт и Xoп (Hirt and Hopp, 1942, стр. 176-177) удалили плодовые тела Phellinus tremulae с 20 деревьев. Через 5 лет 17 из вновь образовавшихся на тех же местах плодовых тел имели пятислойный гименофор. 3 были развиты слабее и имели меньшее количество слоев.

Некоторые авторы утверждают, что иногда в течение одного лета может образоваться два или больше слоев трубочек (Бондарцев, 1953, стр. 62). Конкретно это указано только Бьёрнекером (Bјфrnekaer, 1938, стр. 23) в отношении Fomes fomentarius. Можно предположить, что такое явление в условиях умеренного климата все же только исключение.

У многих видов летом в споруляции наблюдается длительный перерыв. С одной стороны, это объясняется потреблением энергии и питательных веществ гриба для роста гименофора; возможно также, что этот перерыв имеет приспосабливающийся характер - условия для прорастания спор в течение сравнительно сухого периода (летом), по-видимому, неблагоприятные.

Весенний и осенний периоды споруляции происходят в сырое, но прохладное время года. У большинства видов споруляция наблюдается уже при средней температуре $2-3^{\circ}$ и не прекращается под влиянием кратковременных ночных заморозков. При температуре $5-10^{\circ}$ у многих видов отмечается обильная споруляция.

Влажность в'оздуха и ее изменения заметного влияния на споруляцию грибов, растущих на живых деревьях, не имеет. У видов, растущих на валежнике, пнях и т. д., при снижении влажности споруляция ослабевает или прекращается подобно тому, как это наблюдается у большинства однолетних и однолетних-зимующих плодовых тел.

\section{ПРОДОЛЖИТЕЛЬНОСТЬ ЖИЗНИ ПЛОДОВЫХ ТЕЛ И ДЛИТЕЛЬНОСТЬ споруляции}

В приложенных таблицах (табл. 1-3) приводятся сводные данные о продолжительности жизни плодовых тел и длительности споруляции как по наблюдениям автора, так и на основании всех доступных автору литературных источников. Необходимо учесть, что как наши данные, так и данные других авторов получены путем исследования сравнительно малого количества образцов, что не может не отражаться на качестве приводимых результатов. Особенно осторожно нужно относиться к данным, полученным путем исследований в лабораторных условиях (ниже сокращенно «лаб.»).

Указыв'ая данные о продолжительности жизни многолетних плодовых тел, исходили из предположения, что плодовое тело образует каждый год один новый слой гименофора; как было указано выше, такой способ определения возраста не является вполне безошибочным.

Следует отметить, что у экземпляров одного и того же вида, как и у одного и того же экземпляра в разные годы, варьируемость в' продолжительности споруляции довольно велика.

Все же в общем споруляционный период у многих видов довольно продолжительный. Различия в данных отдельных авторов можно объяснить различием методики и, ввиду малого количества наблюдаемых плодовых тел, также и случайностями, а с другой стороны - различием в природных условиях в отдельные годы и в отдельных странах. Длительность споруляции $P h$. igniarius и Ph. tremulae в Ленинградской обл. не- 
сколько меньше, чем в Эстонской ССР. Еще более заметна разница при сравнении с данными споруляции из Дании. Как видно из таблицы, в Дании (по Бьёрнекеру) почти все виды спорулируют дольше (Anisomyces odoratus даже на 4-5 месяцев). Причиной этого является, по-видимому, морской климат Дании - высокая влажность воздуха и недолгая зима; у некоторых видов там наблюдается споруляция даже в январе (средняя температура января в Дании $\left.0-+1^{\circ}\right)$.

\section{ЗАВИСИМОСТЬ СПОРУЛЯЦИИ ОТ ВНЕШНИХ УСЛОВИИ}

В зависимости споруляции от температуры воздуха наиболее интересным является то, что споруляция наблюдается уже при низких температурах - как общее правило у «многолетних» видов, начиная с $2-5^{\circ}$. C повышением температуры споруляция усиливается; при $10^{\circ}$ и выше часто наблюдается уже сильная споруляция. При более высоких температурах (выше $15-20^{\circ}$ ) интенсивность споруляции нередко подавляется сухостью воздуха и субстрата.

Некоторые авторы указывают, что споруляция стимулируется чередованием высоких и низких температур (Hirt, 1932, стр. 8 - у Trametes suaveolens) или повышением температуры выше $10^{\circ}$ после прохладной погоды (Percival, 1933, стр. $39-$ у Phellinus pini). Эти данные требуют еще подтверждения.

Кратковременные ночные заморозки не прекращают споруляции видов с однолетними-зимующими и многолетними плодовыми телами. Понижение температуры ниже $0^{\circ}$ примерно на неделю (с минимальной до $-9^{\circ}$ ) не прекращало совсем споруляционного периода, а только временно приостанавливало его.

Подобные данные имеются и в литературе. Бухвальд (Buchwald, 1938, стр. 69) указывал, что замерзание в течение 1 часа при температуре $-3^{\circ}$ не влияло на споруляцию Fomes fomentarius. Только замерзание, длившееся 24 часа при $-6^{\circ}$ и $-4^{\circ}$, привело к прекращению споруляционного периода. Хирт (Hirt, 1932, стр. 8) провел опыт по замораживанию плодового тела Trametes suaveolens в течение 12-24 часов до $-6^{\circ}$, а затем помещал его в температуру $20-22^{\circ}$, где споруляция начиналась через 8-10 часов. В опытах Бёллера (Buller, 1909, стр. 123-125) слабая спорулящия у Cerrena unicolor, Coriolus versicolor, C. hirsutus и Lenzites betulina в лабораторных условия х продолжалась при температуре $0^{\circ}$, у последнего вида даже в течение 3 дней.

Бёллер (там же, стр. 126) также провел ряд опытов для выяснения влияния высоких температур. Споруляция Lenzites betulina прекращалась при 29-30 . В условиях Эстонской ССР высокую температуру как фактор, препятствующий споруляции, по всей вероятности, учитывать не следует, так как здесь температура только изредка превышает $30^{\circ}$.

Зависимость споруляции от влажности воздуха менее заметна. Многие авторы отрицают роль этого фактора (Buller, 1909, стр. 91 - Polyporus squamosus; White, 1920, стр. 1942 - Fomes fomentarius; Hirt, 1928, стр. 43 - Phellinus gilvus; Percival, 1953, стр. $29-P h$. pini). Борисов (1940, стр. 87) отмечал, что влажность воздуха на начало и ход споруляции у Phellinus igniarius и $P$ h. tremulae, очев'идно, не имела решающего значения. Сильная споруляция наблюдалась одновременно с колебанием влажности, но последняя, в свою очередь, зависит от колебания температуры.

Макдональд (Mac Donald, 1937, стр. 301) отмечал, что плодовые тела Piptoporus betulinus спорулировали в сухом воздухе лаборатории до 15 дней, а под стеклянным колпаком - до 3 недель. Райли (Riley, 1952) указывал, что высокая относительная влажность благоприятствует споруляции Phellinus tremulae.

Некоторые авторы ссылаются на зависимость споруляции от влажности субстрата; с уменьшением последней споруляция ослабевает или 
Таблича 3

\begin{tabular}{|c|c|c|c|}
\hline Виды & 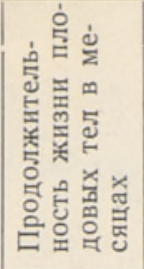 & $\begin{array}{l}\text { Длитель- } \\
\text { ность спору- } \\
\text { ляции в не- } \\
\text { делях }\end{array}$ & $\begin{array}{c}\text { Автор и } \\
\text { примечания }\end{array}$ \\
\hline 1 & 2 & 3 & 4 \\
\hline $\begin{array}{l}\text { Fibuloporia mollusca } \\
\text { Podoporia sanguinolenta } \\
\text { Ceraporia incarnata } \\
\text { Chaetoporus corticola } \\
\text { Hapalopilus fibrillosus } \\
\text { Gloeoporus Bourdotii } \\
\text { G. tschulymicus } \\
\text { Tyromyces lacteus } \\
\text { Tyromyces floriformis } \\
\text { T. erubescens } \\
\text { Laetiporus sulphureus } \\
\text { Piptoporus betulinus } \\
\\
\text { Ischnoderma resinosum } \\
\text { Phaeolus Schweinitzii } \\
\text { Inonotus radiatus } \\
\text { Coltricia perennis } \\
\text { Polyporus squamosus } \\
\text { P. varius } \\
\text { P. picipes } \\
\text { Ganoderma lucidum } \\
\text { Abortiporus borealis } \\
\text { Polyporus basilaris Overh. }\end{array}$ & $\begin{array}{c}>6 \\
>2 \\
<1 \\
1 / 2-2 \\
1-2 \\
1 / 2-2 \\
1-2 \\
11 / 2 \\
21 / 2 \\
1-11 / 2 \\
1-11 / 2 \\
1-4\end{array}$ & $\begin{array}{c}>5 \text { мес. } \\
<1 \text { мес. } \\
2 \\
1-3 \\
2-6 \\
1-2 \\
2-6 \\
2-4 \\
? \\
4 \\
2-4 \\
1-2 \text { мес. } \\
2-3 \\
3 \text { мес. } \\
2-6 \\
2-6 \\
>11 / 2 \text { мес. } \\
\text { неск. дней } \\
14-21 \text { дней } \\
1-2 \\
6 \\
2 \\
2-4 \\
2-6\end{array}$ & $\begin{array}{l}\text { Mac Donald, } \\
1937 \text { (лаб.) } \\
\text { Bjørnekaer, } \\
1938\end{array}$ \\
\hline
\end{tabular}

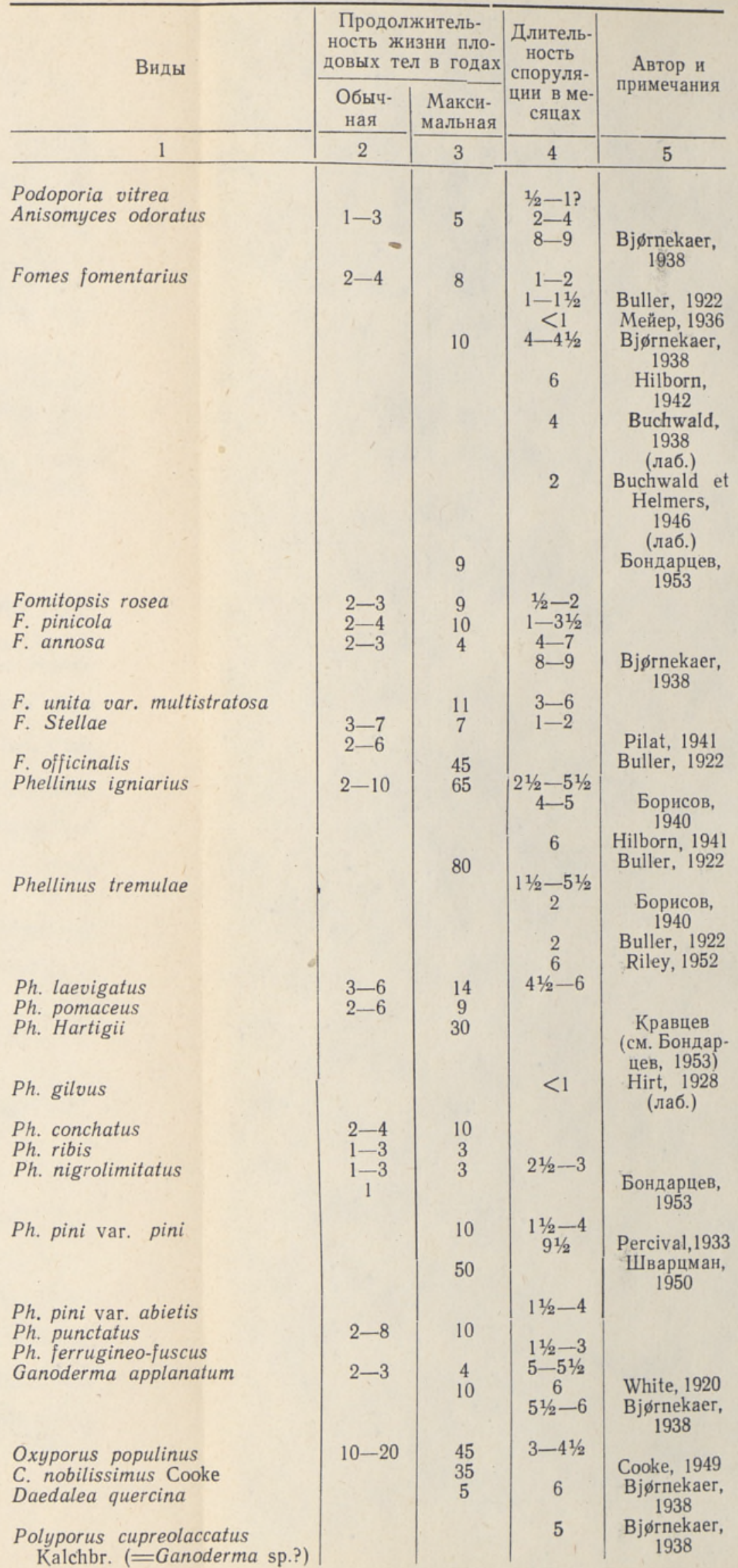

таблица 2

Виды с однолетними-зимующими плодовыми телами

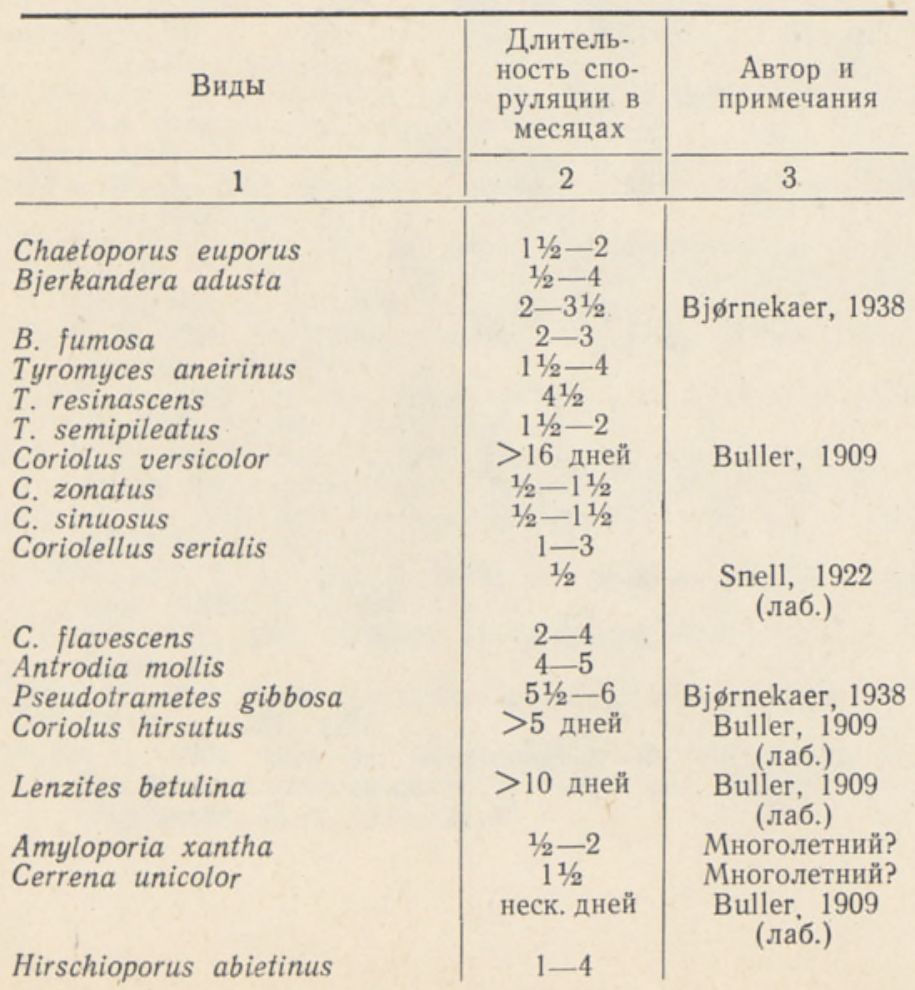


прекращается (White, 1920, стр. 142 - Fomes fomentarius; Hirt, 1928, стр. 13-14-Phellinus gilvus).

В итоге приведенных литературных данных и наших наблюдений можно сказать, что споруляция плодовых тел, обитающих на живых деревьях, имеющих деревянистую консистенцию и покрытых толстой коркой, заметно не зависит от влажности воздуха. У плодовых тел с мясистой консистенцией, не покрытых такой коркой и, главное, обитающих на субстратах с непостоянным содержанием влаги (мелкие остатки древесины и т. д.), эта зависимость выражена ясно. Уменьшение влажности у этих видов' обычно приводит к уменьшению или прекращению споруляции.

Представленные результаты кратковременных наблюдений, конечно, не отражают все разнообразие споруляции трутовых грибов и зависимости ее от экологических условий. В дальнейшем методику подобных наблюдений следует углублять и, в первую очередь, проводить последние в местах с различными климатическими условиями. Только таким путем мы можем дойти до более полного познания процесса размножения и экологии распространения трутовых грибов.

\section{ЛИТЕРАТУРА}

Бонда р це в А. С., 1936. Наблюдения над выбрасыванием спор трутовнком Ganoderma applanatum (Pers.) Pat. Сов. бот., № 6, стр. 144-149.

Б он д а р ц е в А. С., 1953. Трутовые грибы Европейской части СССР и Кавказа. М.-Л.

Бо р.и сов П. Н., 1940. Fomes igniarius Fr. и некоторые его биологические особенности. Центр. н.-и. ин-т лесн. хозяйства, 15 сб. трудов, стр. 78-92.

Ші в а рцм а н С. Р., 1950. Грибные болезни древесных пород Казахстана и меры борьбы с ними. Алма-Ата.

B a iley, H. E., 194la. The Biology of Polyporus basilaris. Bull. Torrey Bot. Club, LXVIII, 2, p. $112-120$.

B a iley, H. E., 1941b. Contributions to the Biology of Polyporus rheades (Pers.) Fries. Bull. Torrey Bot. Club, LXVIII, 3, p. 198-201.

B jørneka er, K., 1938. Undersøgelser over nogle danske Poresvampes Biologi med saerligt Hensyn til deres Sporefaelding. Friesia, II, 1, p. 1-41.

B os e, S. R., 1930. Biology of Wood-Rotting Fungi Common in Forest Areas. Journ. Linnean Soc. London. Botany, XLVIII.

B o u r d ot. H. et G a l z i n, A., 1928. Hyménomycètes de France, I. Paris.

B uchwald, N. F., 1938. Om Sporeproduktionens Størrelse hos Tøndersvampen Polyporus fomentarius (L.) Fr. Friesia, II, 1, p. 42-69.

B uc hw a 1 d, N. F. og $\mathrm{Hel} 1 \mathrm{~m}$ er s, E., 1946. Fotsatte iagttagelser over Sporefaelding hos Tøndersvamp (Polyporus fomentarius (L.) Fr.). Friesia, III, 3, p. 212-216.

B ulle r, A. H. R., 1909, 1922. Researches on Fungi, I; II. London.

Cooke, W. B., 1949. Oxyporus nobilissimus and the Genus Oxyporus in North America. Mycologia, XLI, 4, p. $442-455$.

Hilbor n, M. T., 1941. The Biology of Fomes fomentarius. Phytopath., XXXI, 1, p. 11.

Hilb or n, M. T., 1942. The Biology of Fomes fomentarius. Maine Agric. Exp. Stat. Bull., 409, p. 161-214. (Цит. по Review Appl. Mycol., XXI, 1942, p. 475-476).

Hirt, R. R., 1928. The Biology of Polyporus gilvus (Schw.) Fries. New York St. Coll. Forestry. Tech. Publ., 22.

Hirt, R. R., 1932. On the Biology of Trametes suaveolens (L.) Fries. New York St. Coll. Forestry. Tech. Publ., 37.

Hirt, R. R. and Hop p, H., 1942. Relation of Tube Layers to Age in Sporophores of Fomes igniarius on Aspen. Phytopath., XXXII, 2, p. 176-178.

L o hwa g, K., 1940. Zur Anatomie des Deckgeflechtes der Polyporaceen. Ann. Mycol., XXXVIII, S. $401-452$.

Ma c Donald, J. A., 1937. A Study of Polyporus betulinus (Bull.) Fries. Ann. Appl. Biol, XXIV, 2, p. 289-310.

$\mathrm{M}$ a thiesen, A., 1927. Ulikooli öppemetskond. Tartu Ulikooli Metsaosakonna toimetused, 11 .

Meyer, H., 1936. Spore Formation and Discharge in Fomes fomentarius. Phytopath., XXVI, p. $1155-1156$.

Möller, A., 1904. Uber die Notwendigkeit und Möglichkeit wirksamer Bekämpfung des Kiefernbaumschwammes Trametes pini (Thore) Fries. Zeitschr. Forst- u. Jagdwesen, 36, S. $677-715$, 
P a rm a sto, E., 1956. Juurepessu (Fomitopsis annosa) bioloogiast. Eesti NSV Teaduste Akadeemia Toimetised. Bioloogiline Seeria, V köide, nr. 3, 1k. 256-261.

Percival, W. C., 1933. A Contribution to the Biology of Fomes pini (Thore) Lloyd. New York St. Coll. Forestry. Tech. Publ., 40.

Pilát, A., 1941. Atlas des Champignons de l'Europe. Ser. B. Polyporaceae, fasc. 28-34. Praha.

R i ley, C. G., 1952. Studies in Forest Pathology, IX. Fomes igniarius Decay of Poplar. Canad. Journ. Botany, 30, 6, p. $710-734$.

S ne 11, W. H., 1922. Studies of Certain Fungi of Economic Importance in the Decay of Building Timbers. U. S. Departm. Agric., Bull., 1053.

Ulbrich, E., 1940. Wachstumsbeobachtungen an Fruchtkörpern einiger Polyporaceen und Boletaceen. Notizbl. Bot. Gart. Mus. Berlin-Dahlem, 15, 2, S. 258-278. (Цит. по Review Appl. Mycol., XXII1, 1944, p. 369).

White, J. H., 1920. On the Biology of Fomes applanatus (Pers.) Wallr. Transact. Royal Canad. Inst., XII, 2, No. 28.

Институт зоологии и ботаники

Академии наук' Эстонской ССР

Поступила в редакцию

$26 \times 1957$

\section{TORIKULISTE VILJAKEHADE ARENG JA SPORULATSIOON}

\section{E. Parmasto, \\ blolooglateaduste kandidaat}

\section{Resümee}

Mõnevõrra täiendatud ja parandatud Bjørnekaeri (1938) meetodil läbiviidud statsionaarsed vaatlused Räpina rajoonis 1953 - 1955. a. näitasid, et uuritud 56 liiki torikulisi (220 eksemplari) kuuluvad kolme hästi eristatavasse bioloogilisse rühma.

1. Uhea astaste viljakehadega torikulised. Sila kuuluvad peamiselt alamsugıkondade Porioideae, Tyromycetoideae ja Polyporoideae esindajad. Viljakehad tekivad enamikul liikidel juulis ja augustis ning omandavad 1-2 (erandina kuni 4) nädala jooksul peaaegu normaalsed mōõtmed. Alles siis algab torukeste kihi arenemine ning torukeste $0,5-1 \mathrm{~mm}$ pikkuse juures $2-4$ nädalat kestev sporulatsioon. Uksikutel liikidel võib sporulatsioon kesta ka kauem (Fibuloporia mollusca juures erandjuhtudel isegi kuni 5 kuud). Pärast sporulatsiooniperioodi lōppu viljakehad lagunevad.

2. Oheaastaste talvituvate viljakehadega torikulised. Siia rühma kuuluvad paljud Corioloideae esindajad ning mõned liigid Tyromycetoideae ja Porioideae alamsugukonnast. Viljakehad tekivad ajavahemikus juunist septembrini, kasvades üsna aeglaselt. Sügisene sporulatsiooniperiood algab alles ühe kuu pärast vōi hiljemgi ning kestab enamasti seni, kuni keskmine ööpäevane temperatuur langeb $+2^{\circ} \mathrm{C}$ madalamale, kuni $0^{\circ}$. Osa viljakehasid hävineb, kuid paljud talvituvad ja sporuleerivad ka kevadel pärast keskmise temperatuuri tõusmist üle $+2^{\circ} \mathrm{C}$. Viljakehad lagunevad suve alguses.

3. Mitmeaastaste viljakehadega torikulised kuuluvad peamiselt alamsugukonda Fomitoideae. Viljakehad esinevad juunist vōi juulist septembrini. Samal ajal toimub ka uue torukeste kihi aeglane kasvamine vanematel viljakehadel. Nagu eelmises rühmas, nii siingi toimub sporulatsioon kahel perioodil (esimene - suvel ja sügisel, teine - järgmisel kevadel). Osal liikidel võib üks perioodidest olla nõrgem või isegi puududa. Viljakehade iga enamikul liikidel küünib 5-15 aastani, erandiuhtumeil võib see olla ka suurem (Oxyporus populinus'el kuni 45 aastat, Phellinus igniarius'el kuni 65 aastat).

Torikuliste viljakehade kasvamine toimub reeglipäraselt ainult suvel, vaid erandjuhtudel (näiteks Ganoderma applanatum'i juures) algab see kevadel. Enamikul liikidel (välja arvatud esimene rühm) toimub sporulatsioon kõige rikkalikumalt kevadel (isegi alles lume sulamise ajal) ja sügisel, kestes püsivate külmade saabumiseni. Elavate! puudel kasvavate puitunud viljakehadega torikuliste sporulatsiooni ei mōjusta märgatavalt ôhu niiskussisaldus. Ebapüsiva niiskussisaldusega puidul (väiksemad lamavad tüved, oksad, kännud jms.) kasvavate lihakate viljakehade puhul toob ōhu niiskussisalduse vähenemine kaasa sporulatsiooni nōrgenemise vōi ajutise lakkamise.

Artikli juurde kuuluvais tabeleis esitatakse nii kirjanduses leiduvad kui ka autori andmed viljakehade ea ja sporulatsiooni kestuse kohta. Püstridades on märgitud 1. tabelis: 2 - viljakehade iga kuudes, 3 - sporulatsiooni kestus nädalais; 2 . tabelis: $2-$ sporulatsiooni kestus kuudes; 3 . tabelis: $2-$ viljakehade tavaline iga, $3-$ viljakehade maksimaalne iga, 4 - sporulatsiooni kestus kuudes. 


\section{DEVELOPMENT AND SPORE DISCHARGE OF THE FRUIT-BODIES OF POLYPORACEAE}

\section{E. Parmasto}

\section{Summary}

Stationary observations based on the Bjørnekaer (1938) method, in some degree completed and improved, and carried out in the Räpina District during 1953-1955, showed that the 56 species (220 specimens) examined belong to three well-distinguished biological groups.

1. Polyporaceae with annual fruit-bodies. This group is mainly represented by the subfamilies Porioideae, Tyromycetoideae and Polyporoideae. In most of these species the fruit-bodies appear in July or August and assume almost normal dimensions in the course of $1-2$ (exceptionally even 4 ) weeks. Only then does the development of tubelayers begin and, as soon as the tubes attain a length of $0.5-1 \mathrm{~mm}$, spore discharge sets in and lasts over a period of $12-4$ weeks. In certain species spore discharge may continue still longer (in Fibuloporia mollusca for as long as 5 months). After the end of the spore discharge period the fruit-bodies rot away.

2. Polyporaceae with annual wintering fruit-bodies. To this group belong many species of Corioloideae and some species of the subfamilies Tyromycetoideae and Porioideae. The fruit-bodies appear in the period from June to September, developing rather slowly. The autumn spore discharge does not begin till a month or more later, and in most cases continues till the average daily temperature falls below 0 to $+2^{2} \mathrm{C}$. Part of the fruit-bodies is destroyed, but many of them survive the winter and resume spore discharge in spring, after the average temperature has risen above $2^{\circ} \mathrm{C}$. The fruit-bodies begin to rot away at the beginning of summer.

3. Polyporaceae with perennial fruit-bodies. Most of them belong to the subfamily Fomitoideae. The new fruit-bodies appear from June or July up to September, during which period the tube-layers oi the old fruit-bodies continue to grow slowly. As in the former group, there are two periods of spore discharge - the first in summer and autumn, and the second in the following spring. In some species one of these periods may be weaker or even entirely absent. In most species the age of the fruit-bodies is from 5 to 15 years, exceeding these limits only in exceptional cases (Oxyporus populinus may attain an age of 45 , Phellinus igniarius - of 65 years).

As a rule, the growth of the fruit-bodies of Polyporaceae takes place exclusively during the summer, and only in exceptional cases (for example Ganoderma applanatum) does it begin in spring. In most species (apart from the first group) spore discharge is most plentiful in spring (occurring during the thaw) and in autumn, lasting up to the beginning of persistent irosts. The moisture content of the air does not considerably affect the spore discharge of Polyporaceae with woody fruit-bodies growing on living trees. Diminution of the moisture content of the air will cause a temporary weakening or even ceasing of the spore discharge of fleshy fruit-bodies growing on wood with inconstant moisture contents (small logs, loose branches, stumps etc.).

The Tables 1, 2 and 3 refer to the data given by literature as well as those obtained by the author for the life duration and spore discharge of the fruit-bodies investigated. The columns on Table 1 indicate respectively: (2) - the average age in months, and (3) - the duration of spore discharge in weeks. Table 2, col. 2 gives the duration of spore discharge in months. Table 3 , col. 2 gives the normal age, col. 3 the maximum age, and col. 4 - the duration of spore discharge in months.

Academy of Sciences of the Estonian S. S. R.,

Received Institute of Zoology and Botany 